\title{
O COMPLEXO CULTURAL E O COMPLEXO DO COMER: UM ESTUDO COM MULHERES OBESAS
}

\author{
The Cultural Complex and the Complex of Eating: A Study With Obese Women \\ El Complejo Cultural y el Complejo de Comer: Un Estudio con Mujeres Obesas
}

MARia do DesterRo de FigUeiredo STELLA NABUCO NASSER Armando de Oliveira e SiLva ROSANA BENTO RADOMINSKI

\begin{abstract}
Resumo: A obesidade é considerada um problema epidêmico, que acarreta graves prejuízos na saúde física e emocional dos indivíduos. Em busca de investigar os fenômenos psicológicos e culturais envolvidos na obesidade, propõe-se uma visão compreensiva-simbólica dos discursos de mulheres obesas pacientes de um Hospital Geral em Curitiba-Pr. O estudo baseou-se em constructos teóricos como: a Teoria dos Complexos para Jung, o Inconsciente Cultural para Henderson, o Complexo Cultural para Singer e Kimbles. A partir desses visa-se propor um novo constructo teórico: o Complexo do Comer, que é representado pelas experiências vinculadas ao tema alimentação, e relacioná-lo com o Complexo Cultural. Observa-se, a partir dos discursos, que ambos os Complexos expressam-se, paradoxalmente, a forma de incorporar ideias inconscientes de um corpo ideal, que repousam em uma imagem arquetípica da fome e da falta. Num contexto da saúde, esta falta marca a necessidade de um preencher que muitas vezes se faz excessivo e desnaturado, a qual deve ser considerada no tratamento multidisciplinar da obesidade, por meio de estratégias terapêuticas que contemplem essa realidade e a visão de totalidade psíquica.
\end{abstract}

Palavras-chave: Complexo; Cultura; Comer; Obesidade; Mulheres; Psicologia Analítica.

Abstract: Obesity is considered an epidemic problem, which causes serious damage to the physical and emotional health of individuals. In order to investigate the psychological and cultural phenomena involved in obesity, we propouse a comprehensive and symbolic view of the discourses of obese women, patients from a General Hospital in Curitiba-Pr. The study was based on theoretical constructs such as: Jung's Complex Theory, Henderson's Cultural Unconscious, Singer and Kimbles' Cultural Complex. From these theories, it is aimed to propose a new theoretical construct: the Eating Complex, which is represented by experiences related to the theme of food, and relate it to the Cultural Complex. It is observed from the discourses that both Complexes paradoxically express themselves in a way to incorporate unconscious ideas of an ideal body, that rests in an archetypal image of hunger and lack. In a context of health, this lack marks the need for a filling that is often excessive and denatured, which should be considered in the multidisciplinary treatment of obesity, through therapeutic strategies that contemplate this reality and the vision of psyche totality.

Key words: Complex; Culture; Eating; Obesity; Women; Analytical Psychology.

Resumen: La obesidad es considerada un problema epidémico, que acarrea graves perjuicios en la salud física y emocional de los individuos. En busca de investigar los fenómenos psicológicos y culturales involucrados en la obesidad, se propone una visión comprensiva-simbólica de los discursos de mujeres obesas pacientes de un Hospital General en Curitiba-Pr. El estudio se basó en constructos teóricos como: la Teoría de los Complejos para Jung, el Inconsciente Cultural para Henderson, el Complejo Cultural para Singer y Kimbles. A partir de estos se pretende proponer un nuevo constructo teórico: el Complejo del Comer, que es representado por las experiencias vinculadas al tema alimentación, y relacionarlo con el Complejo Cultural. Se observa, a partir de los discursos, que ambos Complejos se expresan paradójicamente la forma de incorporar ideas inconscientes de un cuerpo ideal, que reposan en una imagen arquetípica del hambre y de la falta. En un contexto de la salud, esta falta marca la necesidad de un relleno que muchas veces se hace excesivo y desnaturalizado, la cual debe ser considerada en el tratamiento multidisciplinario de la obesidad, a través de estrategias terapéuticas que contemplen esa realidad y la visión de totalidad psíquica.

Palabras-clave: Complejo; Cultura; Comer; Obesidad; Mujeres; Psicología Analítica. 


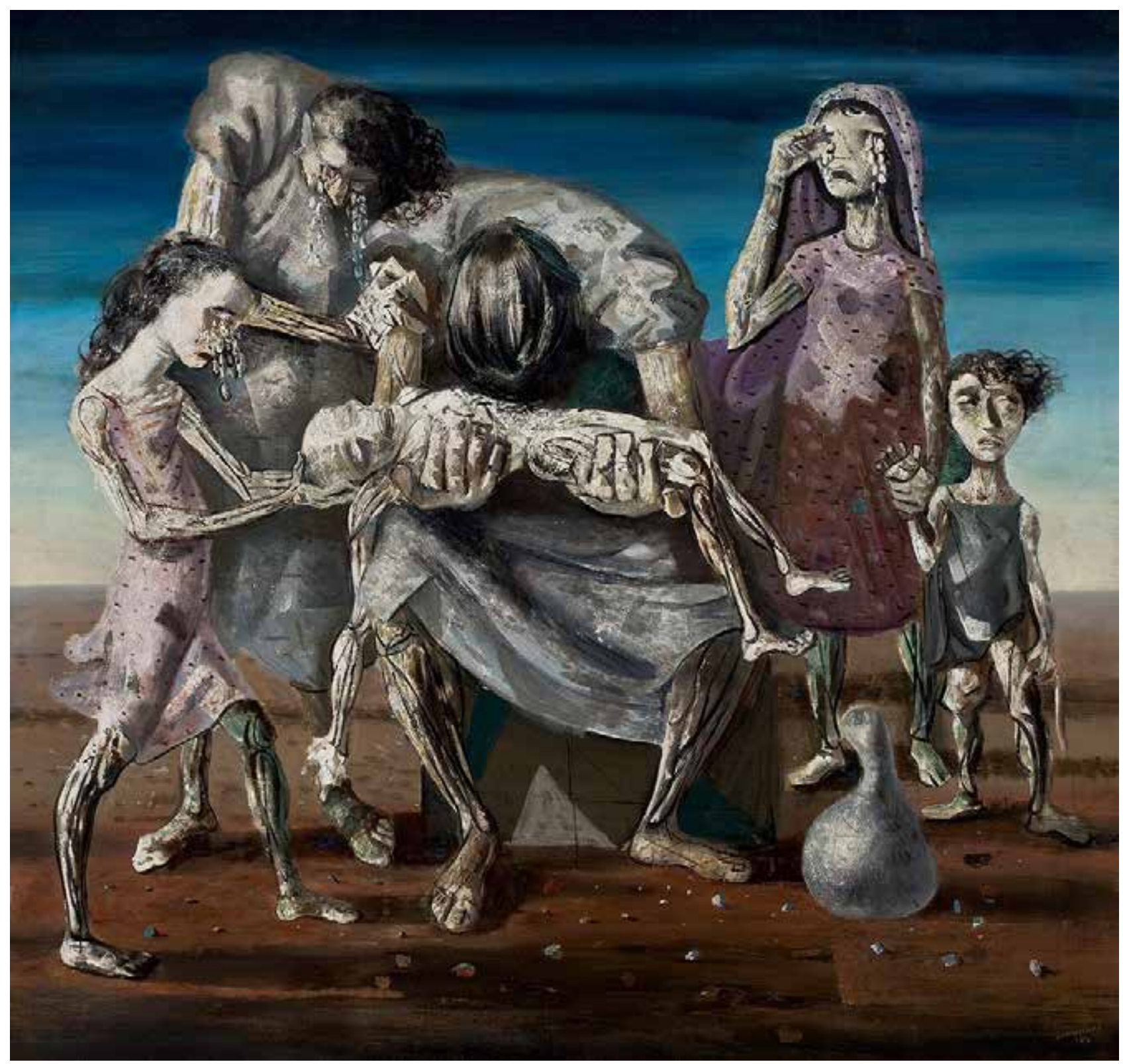

Figura 1. Criança morta de Cândido Portinari.

Fonte: https://masp.org.br/acervo/obra/crianca-morta (acesso em: 25 de março de 2019)

\section{Introdução}

It has been written somewhere that 'to depart is to die a little'. Dali Says that, without any doubt, to eat - especially gastronomical repasts - is always

‘to die a lot”’. (Dalí, 2016)

O estudo da cultura e seus efeitos na psique tem se mostrado de grande relevância em meio às evoluções tecnológicas e científicas, que são perpassadas por crises sociais e culturais. As teorias que englobam a Cultura, na Psicologia Análitica, se propoem em vários momentos a compreender essas crises a partir de conceitos dado por Carl Gustav Jung. Neste cenário, Joseph Henderson (1984) - aluno de Jung, define quatro atitudes culturais: a social, a religiosa, a estética e a filosófica que são propagadas com o ob- jetivo de manter um código ético dentro de uma cultura específica. Já Kimbles (2000) e Singer e Kimbles (2004), tentam desvendar as guerras e rivalidades entre as culturas a partir do estudo da Psique. Ramos (2004), por sua vez, focaliza seu estudo no Brasil, com os questionamentos acerca da Corrupção e do Complexo Cultural brasileiro e Araújo (2002), desvenda a questão da diversidade étnica por meio do estudo do inconsciente cultural. Já na esfera sobre a cultura e o fenômeno do comer, Woodman (2002), estuda a questão da obesidade no gênero feminino e suas implicações sociais.

Esse trabalho propõe o estudo do Complexo Cultural e do Complexo do Comer e suas expressões no comportamento alimentar, assim como a relação da mulher obesa com seu corpo em um contexto brasileiro. Para tanto se faz necessário uma trajetória te- 
órica que contemple as esferas do Inconsciente Cultural, dos Complexos e do Complexo Cultural como influenciadores do Complexo do Comer.

A fim de iniciar a reflexão, é necessário localizar o leitor acerca da cultura brasileira. Para tal fim utiliza-se do quadro "Criança Morta" de Cândido Portinari de 1944. O quadro retrata uma realidade brasileira e arquetípica - a fome. Em 1975, segundo dados do Instituto Brasileiro de Geografia e Estatística (IBGE), a prevalência de desnutrição infantil no Brasil era de 18,4\%. Apesar desse parâmetro ter, em 2009, baixado para $2,9 \%$, a fome ainda é uma realidade em que marca as representações simbólicas e culturais do brasileiro.

Aqui surge o questionamento: porque falar de fome, se o presente trabalho aborda sobre o fenômeno da obesidade? A teoria de Jung retrata sobre a importância dos opostos complementares no fluxo natural da vida, destacando que "é no oposto que se acende a chama da vida” (p. 65) isto é, a energia só é produzida onde há tensão entre os contrários (Jung, 2011b). Desta forma, propõe-se a integração desses opostos enquanto busca pela totalidade como união de todos os sistemas e conteúdos conscientes e inconscientes (Nasser, 2010; Jung, 2011g), implícita no processo de individuação. O processo de individuação é um processo complexo que implica em:

Individuação significa torna-se um ser único, na medida em que por 'individualidade' entendemos nossa singularidade mais íntima, última e incomparável, significando também que nos tornamos o nosso próprio si-mesmo. Podemos pois traduzir 'individuação' como 'tornar-se si-mesmo' (Verselbstung) ou 'o realizar-se do si-mesmo’ (Selbstwerwirklichung) (Jung, 2011c. p. 64).

Já em uma perspectiva da psicologia analítica, Jung reconhece a importância e a necessidade do estudo acerca do comportamento grupal. "O neurótico é apenas um caso específico de pessoa humana em conflito consigo mesma, tentando conciliar, dentro de si, natureza e cultura." (Jung, 2011b, p. 30). Entretanto, ao estudar as manifestações coletivas, o autor atribui essas ações a níveis arquetípicos da psique. Para Kimbles (2000) e Singer e Kimbles (2004), a noção junguiana acerca do coletivo é influenciado pelas esferas individuais do sujeito como o inconsciente individual e também o inconsciente coletivo, como representante do nível arquetípico e expressas por meio das imagens arquetípicas.

Por sua vez, em uma perspectiva contemporânea da Psicologia Analítica, é conceituado o termo Complexo Cultural enquanto as manifestações individuais e grupais, influenciadas pela cultura e marcadas por um inconsciente cultural (Kimbles, 2000; Singer \& Kimbles, 2004).

Esses constructos teóricos estão interligados a estudos e releituras da teoria de Jung, tais como a te- oria dos Complexos, do Inconsciente Coletivo e dos Instintos. O conceito de Inconsciente Cultural, e.g., foi introduzido por Joseph Henderson em 1984, em sua obra Cultural Attitudes in psychological perspective (Araújo, 2002). Já o conceito de Complexo Cultural teve seu início nos anos 2000, com Singer e Kimbles, a partir de estudos dos conflitos grupais que aterrorizavam os EUA (Kimbles, 2000). Woodman (2002) traz o conceito de Complexo da Alimentação enquanto uma expressão dos conflitos psíquicos relacionados ao comer.

\section{Desenvolvimento}

\section{Os Complexos na Psicologia Analítica}

A fim de uma compreensão aprofundada sobre o Complexo Cultural e sua influência no Complexo do Comer na Cultura Brasileira, se faz necessário conceituar o termo Complexos na Psicologia Analítica. Este foi aplicado, inicialmente, por Carl Gustav Jung, no Hospital Psiquiátrico Burgholzli, entre 1904-1906, junto com Franz Riklin e publicado como Estudos Diagnósticos das Associações. O conceito foi desenvolvido por meio das observações e constatações através do instrumento Teste de Associação das Palavras, que se tratava de um experimento clínico em que frente a algumas palavras-estímulos, pessoas sadias e não sadias psiquicamente, foram estudadas e tinham expressões adversas, como erros, demoras e desconcertos, (Jung, 2011a). As palavras-estímulos são representadas como uma parte da realidade que atua em nós, sendo que, a partir deste experimento, ao reagir a essas de forma perturbada entendem-se que uma pessoa esteja "deficientemente adaptada à realidade”, ou seja com um distúrbio funcional da mente (Jung, 2011c; p. 498).

Os fatores psíquicos perturbatórios e suas manifestações na psique foram denominados de complexos de acento emocional e mais tarde, apenas de complexos (Jacobi, 2017). Por Complexo pode-se entender um agrupamento de representações mentais, os quais se organizam a partir de experiências emocionais significativas do sujeito, constituído de portador de significado e, em torno de uma raiz ou núcleo arquetípico, sendo ainda, "a imagem de uma determinada situação psíquica de forte carga emocional e, além disso, incompatível com as disposições ou atitude habitual da consciência." (Jung, 2011d, p. 43).

Os Complexos são elementos psíquicos que ocorrem naturalmente no indivíduo que busca estruturar as respostas individuais a dados biológicos e as diversas situações arquetípicas da vida, isto é, estes não são necessariamente de ordem patológica. Caracterizam-se como fator psíquico que supera o valor, em termos de energia, das intenções conscientes do sujeito e é dotada de certa autonomia que pode controlar condutas e comportamentos humanos (Jung, 2011d). Essa tonicidade ou força emocio- 
nal é frisada pelo autor ao trazer que, "Hoje em dia todo mundo sabe que as pessoas 'têm complexos'. Mas o que não é bem conhecido e, embora teoricamente seja de maior importância, é que os complexos podem nos ter” (Jung, 2011d, p. 43). Contudo, para o autor, com o uso da vontade é possível que o Complexo seja reprimido, mas nunca negado - uma vez que, “e na primeira ocasião favorável ele volta à tona com toda a sua força original.” (Jung, 2011d, p. 44). Esse fenômeno é explicado, quando há uma constelação, que é definido por Jung (2011d, p. 41) como:

Este termo exprime o fato de que a situação exterior desencadeia um processo psíquico que consiste na aglutinação e na atualização de determinados conteúdos. A expressão "está constelado” indica que o indivíduo adotou uma atitude preparatória e de expectativa, com base na qual reagirá de forma inteiramente definida. A constelação é um processo automático que ninguém pode deter por vontade. Esses conteúdos constelados são determinados complexos que possuem energia específica própria.

\section{Inconsciente Cultural}

A partir da ideia de Complexos de Jung, Singer e Kimbles (2004) definem Complexo Cultural como decorrente do Inconsciente Cultural em interação com a esfera individual e arquetípica da psique e o mundo. O Inconsciente Cultural, como conceituado por Joseph Henderson, está topologicamente situado entre o Inconsciente Coletivo e Inconsciente Pessoal (FIGURA 2), ou seja, há uma relação estreita entre o Inconsciente Cultural e os fatores arquetípicos (Araújo, 2002; Gozawa, 2009).

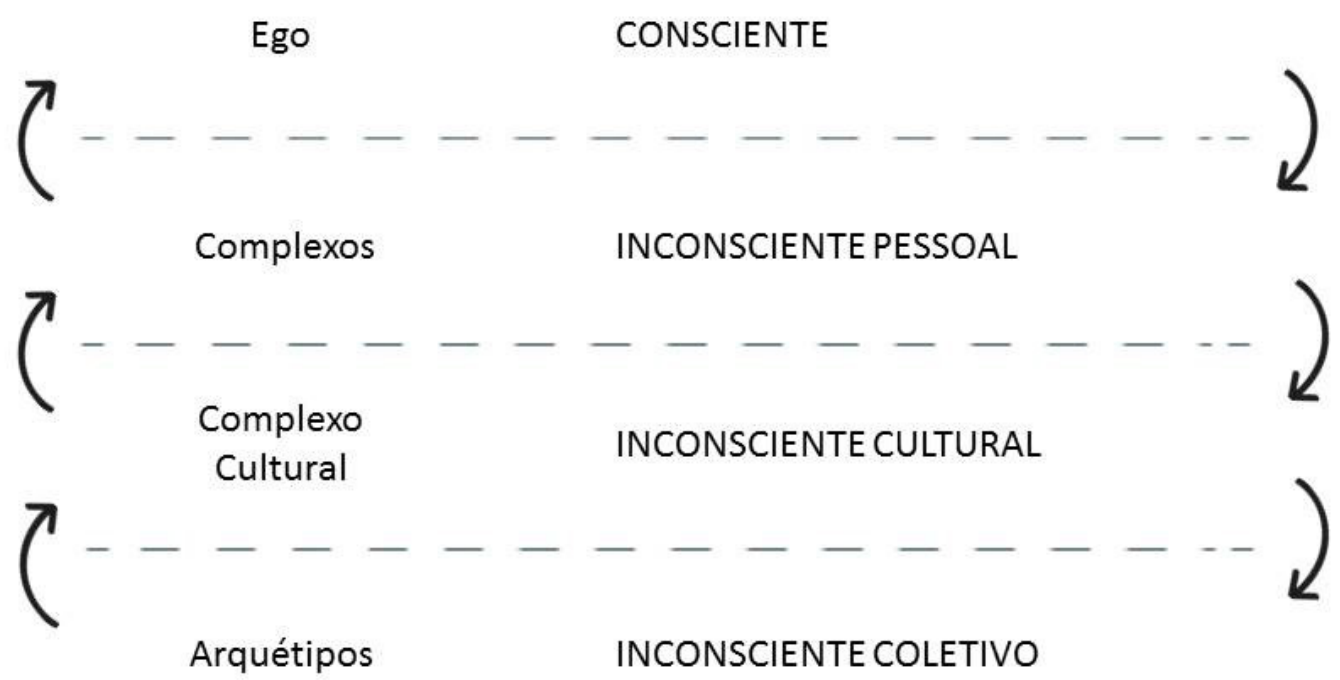

Figura 2. Disposição topológica do Inconsciente Cultural. Fonte: Os autores (2019).

Gozawa (2009), descreve que o Inconsciente Cultural é apenas acessível se for além dos conteúdos individuais da Psique e faz-se necessário explorar as propensões culturais para a investigação daquele. O Inconsciente Cultural diz respeito à adaptação humana à sua existência e sua relação com os arquétipos. Kimbles (2014), retrata o Inconsciente Cultural como um sistema dinâmico de interações, o qual opera-se além do individual e perpassa com o senso de si próprio do indivíduo, permitindo sentimentos de pertença, alienação, identificação ou diferenciação do grupo (Kimbles, 2014).

\section{Complexo Cultural}

Uma vez conceituado o Inconsciente Cultural, é possível voltar-se ao Complexo Cultural. Singer e Kimbles (2004), relatam que o fato de Jung não considerar o nível cultural da Psique, é explicado devido às suas experiências negativas com o cultural (i.e. ter vivenciado guerras). No entanto, Yakushko et al., (2016) expõem que os mitos e rituais, para Jung, foram tomados como produções culturais, e isso apontou a existência de um Inconsciente Coletivo, no pensamento Junguiano. Não obstante, Jung valoriza o indivíduo como um ser social e coletivo, trazendo o valor desse pensamento ao se referir a uma psique coletiva.

Aproximar-nos-emos mais da verdade se pensarmos que nossa psique consciente e pessoal repousa sobre a ampla base de uma disposição psíquica herdada e universal, cuja natureza é inconsciente; a relação da psique pessoal com a psique coletiva corresponde, mais ou menos, à relação do indivíduo com a sociedade. Do mesmo modo que o indivíduo não é apenas um ser singular e separado, mas também um ser social, a psique humana também não é algo de isolado e totalmente individual, mas também um fenômeno coletivo (Jung, 2011c, p. 35). 
Autores (Kimbles, 2000; Singer \& Kimbles, 2004; Gozawa, 2009) relatam o Complexo Cultural como uma terceira esfera da Psique. Por se tratar de conteúdos grupais inconscientes, este tem um funcionamento autônomo, resistente à consciência e é repetitivo. O Complexo Cultural tem característica bipolar, sendo uma parte dele identificada com o grupo e outra projetada a um terceiro (Singer e Kimbles, 2004).

Para Singer e Kimbles (2004), o Complexo Cultural opera tanto no Inconsciente Pessoal (psique pessoal), como no Inconsciente Coletivo (psique coletiva), sendo marcado por uma intensa emoção coletiva. Este tem uma relação dinâmica com o Inconsciente Coletivo, isto é, no núcleo do Complexo Cultural repousa um padrão arquetípico. O produto do Complexo Cultural, de acordo com os autores, é uma teia potente de histórias e emoções sobre o lugar de um grupo, ou nesse caso, de um indivíduo em relação ao mundo em que vive (Singer e Kimbles, 2004).

\section{Complexo do Comer}

Alicerçados pela Teoria dos Complexos de Jung e a consideração de sua pertença a certas categorias, é possível pensar existir tantos complexos como situações arquetípicas na vida. Em paralelo e corroborando com as ideias já mencionadas por Woodman (2002) sobre o Complexo Alimentar, buscou-se neste estudo compreender a atuação de um complexo, enquanto fator psíquico, que representa e expressa a relação emocional com o comer no ser humano - O Complexo do Comer.

Woodman (2002), ao incluir a gordura como um sintoma psíquico, descreve o Complexo Alimentar como uma neurose, ou seja, como uma possibilidade de expressão das necessidades emocionais no indivíduo, as quais geralmente estão relacionadas com a dualidade mãe-filha. Para a autora, a obesidade pode ser a manifestação simbólica e visível desses complexos. Destaca que é necessária a conscientização da expressão psíquica para lidar de forma real e criativa com os impulsos inconscientes que estão por trás do alimento e, com isso, interromper a psicossomatização. Menciona que a "menina gorda" se torna refém do olhar da cultura. Culturalmente, no Brasil, a gordura é visto como tabu e, nesta perspectiva, a mulher obesa sofre com as feridas do próprio ego feminino, sentindo-se rejeitada e isolada, socialmente, pela falta do corpo atraente e feminino (Busse, 2004). De forma geral, mergulha em seu próprio mundo e compensa o que não viveu na realidade por meio das fantasias e atuações muitas vezes destrutivas. Para Woodman (2002), essa mulher mergulha em seu próprio mundo psíquico e compensa o que não viveu em sua realidade por meio das suas fantasias e atuações que são muitas vezes destrutivas para o seu processo.

A cultura endossa o valor do comer enquanto ato representativo e catalisador das emoções, podendo expressar sentimentos positivos e/ou negativos. $\mathrm{Na}$ obesa e em indivíduos com transtornos alimentares há a identificação do uso do alimento enquanto mediador das expressões, ficando esses aspectos claros nas idéias de Woodman (2002) ao postular que, "O alimento e a qualidade do alimento estão no centro de todas as comemorações. Partilhar de um alimento é fazer parte da festa, rejeitá-lo é ser deixado de fora da vida." (p.29).

O Complexo do Comer está unido ao conceito da psiquificação dos instintos, mais propriamente o da fome (Jung, 2011d). O autor relata a existência de cinco instintos: Fome, Sexualidade, Criatividade, Reflexão e Atividade. Estes podem percorrer, nos seres humanos, pelo processo da psiquificação, nos quais ao se ligarem à consciência, são transformados em outros fins que ultrapassam a esfera das necessidades fisiológicas. Com a transformação das necessidades psíquicas humanas, o instinto psiquificado da fome encontra outras formas de se relacionar com o alimento, permitindo significados e representações simbólicos ao ato alimentar (Jung, 2011d).

O Complexo do Comer é entendido enquanto o fator psíquico que representa as mais diversas experiências do sujeito em torno do tema alimentação. Este estaria relacionado aos comportamentos alimentares vivenciados, os quais podem ter associações, positivas ou negativas, experienciadas durante a infância ou mesmo na fase adulta. Ou seja, este complexo está relacionado as faltas e os excessos alimentares que perpassam as faltas e os excessos da vida, tais como os sentimentos, relações e percepções. O Complexo do Comer emocional se expressa no comportamento alimentar disfuncional geralmente em momentos de incertezas e conflitos emocionais que assaltam e tiram o controle alimentar consciente do sujeito.

Sobre o ponto de vista psicodinâmico, a obesidade, assim como os demais sintomas de ordem emocional no obeso, poderiam expressar os conflitos psíquicos (Woodman, 2001), envolvidos nessa experiência corpórea sustentado por um desejo de beleza e aceitação social. Paradoxalmente, a sociedade cobra grandes "tostões" de limites e ajustes, mas também cede e permite exageros calóricos aos "pobres corpos mortais", sob condições de pesados juros a serem pagos por meio da culpa e dos rituais desnaturados, representados tanto pelas radicais dietas como pelas restrições calóricas.

\section{Método}

Esse artigo se refere a uma parte de um estudo maior voltado à pesquisa observacional e descritiva de 120 mulheres com histórico de obesidade em tratamento clínico e cirúrgico, no Hospital Geral em Curitiba-PR. Apresentou enfoque metodológico qualitativo dos dados clínicos e dos fenômenos psicológicos, expressos nos discursos das participantes. To- 
das as participantes foram devidamente informadas sobre os motivos e desenvolvimento do estudo e assinaram o Termo de Consentimento Livre e Esclarecido. A investigação clínica ocorreu, entre novembro de 2016 a junho de 2018, logo após ser submetida às apreciações do comitê de ética da UFPR e aprovada com o parecer de número 59996016.9.0000.0096, do CAAE - Certificado de apresentação para apreciação ética. As análises dos discursos serão apresentadas de forma não sistematizada, considerando a expressão dos fenômenos nas participantes.

\section{O Discurso}

O Inconsciente, na perspectiva junguiana, é somente possível de acessar através da consciência, mas também pode ser investigado e conhecido de forma indireta por meio das manifestações simbólicas arquetípicas (Penna, 2004). O símbolo, de acordo com a autora, "congrega o âmbito pessoal e o âmbito coletivo, a dimensão histórica e a dimensão universal dos fenômenos psíquicos” (Penna, 2004, p. 83), e a fim de endossar a presente temática, o símbolo também repousa num âmbito cultural. Neste artigo, a manifestação simbólica se deu por meio dos relatos das participantes do estudo.

\section{Método Compreensivo-Simbólico}

Os discursos das participantes foram coletados durante as entrevistas e analisados por meio do método compreensivo-simbólico (Penna, 2004). Este método tem como objetivo a noção compreensiva e interpretativa da realidade em que os fenômenos psíquicos se apresentam, sendo que isso pressupõe uma "[...] relação íntima entre o pesquisador e o que é estudado, e os limites situacionais da investigação.” (Denzin \& Lincoln, 1998, p. 8 apud Penna, 2004).

Deve-se estabelecer uma relação dialética entre o sujeito e o objeto - buscando a intersubjetividade dos fatores envolvidos no estudo. De forma dinâmica e inconsciente, a personalidade do pesquisador interfere no fenômeno pesquisado, ou seja, o "conhecimento e autoconhecimento são indissociáveis e condicionados pela psique do pesquisador" (Penna, 2004, p. 76). Yakushko et al. (2016), descrevem sobre a presença e influência do Inconsciente Cultural do pesquisador dentro da pesquisa, principalmente nos estudos qualitativos. Os autores relatam a necessidade de reconhecer os próprios Complexos Culturais por meio do processo terapêutico.

\section{Resultados e Discussão}

A Cultura vigente torna-se altamente excludente ao reforçar as imagens públicas de um corpo ideal. Nesta impera a busca pelo belo e rechaça a gordura, deixando traços subliminares na vida de todos aqueles que não alcançam esse padrão. A mulher obesa encontra-se refém dos ideais externos de um Complexo Cultural e das necessidades e vontades internas do Complexo do Comer. Segundo Woodman (2001, p.7): "A corpulência já teve conotações de felicidade. As pessoas "riam e engordavam"; os poucos mais afortunados "viviam na abundância" e os inúmeros menos afortunados invejavam os "gatos gordos"."

\section{Compreensão simbólica dos discursos - o Corpo e o Comer Obeso}

Levando em consideração o Inconsciente Cultural, Yakushko et al. (2016, p. 659, tradução nossa) relatam que "a incorporação inconsciente de ideias e crenças opressoras podem ocorrer não apenas entre o grupo dominante, mas também entre aqueles que são oprimidos e marginalizados". Nas entrevistas com as participantes do estudo, ao serem perguntadas sobre as consequências negativas do ganho do peso, estas respondem: "Nada é bom na vida depois que ganha peso" (P1). Essa afirmativa diz respeito a uma ideia incorporada, inconscientemente, de que ser gorda é o mesmo que não pertencer a um padrão, ser negativo, excluído e não percebido como pessoa. Esta percepção é reforçada ao serem questionadas sobre como gostariam de ser vistas na sociedade, e respondem: "ser vista como pessoa" (P2); "Gostaria apenas de ser vista" (P3).

Também, nesta ótica, torna-se imprescindível considerar a influência do Complexo do Cultural brasileiro na expressão do Complexo do Comer dos indivíduos. DaMatta (1986, p.11) escreve: "Sei, então, que sou brasileiro e não norte-americano, porque gosto de comer feijoada e não hambúrguer". Essa afirmativa traz o pensar no que faz do comer brasileiro tão específico e distinto do resto do mundo. As possíveis respostas implicam adentrar na esfera cultural. "Encher a pança", "olho maior do que a barriga", ou até nomear o ato sexual como um ato do "comer", como frases cotidianas que moldam e ditam o relacionamento com a comida. (DaMatta, 1986). Afinal, o Complexo Cultural, enquanto emoção coletiva intensa, carrega experiências paradoxais sobre a comida.

Esse fenômeno se apresenta nos discursos das participantes ao serem perguntadas sobre "Para você, o que significa comer?", diversas participantes respondem: "Prazer", outras apenas "Satisfação", "Felicidade". Os discursos revelam a psiquificação do Instinto da Fome, próprio do Complexo Cultural, em que o comer não está somente na ordem do se nutrir, mas também do prazer, satisfação, felicidade. Ou então, nos relatos "Me acalma, porque sou muito sozinha." (P10); "Viver, se não comer não vive" (P11); "Tudo, eu tenho que ter outras atividades, outro foco." (P12).

Contudo, enquanto a maioria das participantes revela uma relação positiva com o comer, algumas ao discorrer sobre o significado do comer, respondem: "Ultimamente, uma tragédia total, prefiro não precisar comer" (P16); "Engordar, ficar gorda” (P17); 
"Eu amo comer, mas não é bom; "É gostoso, mas depois vem o arrependimento" (P18); "Comer passa o estresse depois se arrepende” (P20). Relatos, estes, que demonstram a forma paradoxal e plural do Complexo do Comer.

Compreensão simbólica dos discursos - O feminino e a Falta

Neste constructo, o dinamismo psicológico feminino , representa, arquetipicamente, a força natural e anímica que possibilita as relações consigo e com o mundo (Jung, 2011f; Gadotti, Borges \& Sampaio, 2017). Assim, deve-se considerar a presença da noção de feminino que cerca todo o tema e traz o refletir sobre: qual o lugar deste princípio feminino na discussão sobre o Complexo Cultural e do Comer?

Gadotti, Borges e Sampaio (2017), ao fazerem um relato histórico no que tange o papel e a representação da mulher na sociedade, indicam como o feminino tem sido sufocado em uma dinâmica racionalista e capitalista. Isto é, o feminino que é arquetipicamente o representante de um pensamento simbólico, frente à instalação de um discurso racional e lógico patriarcal, é sufocado. Nisto, como relatam as autoras (2017, p. 51), a "[...] natureza feminina vem sendo sacrificada em nome de uma consciência unilateral baseada no pensamento lógico e racional, tão distante da linguagem anímica e simbólica própria dos mitos, dos sonhos e do feminino.”. Esta, que é sacrificada, traz uma perda de significados, em que há uma anulação entre as diferenças do eu e outro. Essa diferenciação geraria um vazio, o qual antes era suprido por um pensamento simbólico e agora é abolido nesta dinâmica. A falta do vazio empobrece a capacidade simbólica e imagética do ser humano e, mais propriamente, a da mulher (Gadotti et al., 2017).

Nesta perspectiva, o Complexo Cultural e o Complexo do Comer, compreendidos em mulheres obesas, trazem um possível padrão arquetípico expresso pelo vazio e pela falta. A fim de investigá-lo, elenca-se a expressão "Matar a Fome", a qual foi trazida repetitivamente pelas participantes e também usada, cotidianamente, pelos brasileiros. Essa expressão por diversas vezes foi relatada pelas participantes, em um sentido afetivo, ultrapassando um sentido biológico de fome e diz respeito a um caráter psíquico de não lidar com a falta. As histórias contadas por estas, sobre passar fome em momentos da vida, marcaram sua presença nos episódios de compulsão alimentar: "Vou comer hoje, porque vai que amanhã não tem” (P. 47); "Hoje eu como uma bandeja de danoninho, porque antes eu não comia nem um potinho" (P. 23). Assim, a obesidade viria como uma garantia contra os sentimentos ligados a falta.

\section{Considerações Finais}

A busca pela totalidade do sujeito, proposta por Jung (2011g), pressupõe a necessidade de loca- lizá-lo em todas as esferas que o influenciam, tais como a Pessoal, a Coletiva e a Cultural. Considerando que "[...] um dos objetivos do tratamento analítico é auxiliar o sujeito a lidar com seus complexos [...]” (Nasser, 2010, p. 328), a compreensão acerca do Complexo Cultural e do Comer é indispensável no processo de individuação do sujeito, na busca de ser todo.

A experiência obesa, na perspectiva do Complexo Cultural e do Comer, se mostra ambivalente e paradoxal. Observa-se participantes com relações plurais com o comer e com o seu corpo. Junto a isto, percebe-se ideias incorporadas pelo Inconsciente Cultural dos indivíduos, no que tange a busca de um corpo ideal. Esta busca vem em favor de uma falta de significados e uma indigestão simbólica em relação às experiências com o corpo e da vida. Como relata Gadotti et al. (2017, p. 53), "Assim como o processo digestivo transforma o alimento em nutriente, incorporamos e damos significado à experiência, somente depois de uma elaboração psíquica. Precisamos digerir a experiência para que ela se transforme em um alimento para a alma.”.

Neste contexto, poderia-se pensar que a "Gor-Dura”, exposta no corpo obeso, estaria expressando a dificuldade de metabolizar os conflitos entre o que se busca e o que se tem? O "duro" neste cenário estaria, simbolicamente, representando a esfera do não digerido e absorvido do conteúdo psíquico. Teria então os "pobres corpos obesos” o trágico destino corpóreo a ser transformado pela misericórdia dos deuses? Ou teriam eles a ilusão prometida das revolucionárias técnicas cirúrgicas ou dos poderosos medicamentos como novos mitos que os levariam ao trono da beleza? São reflexões que se fazem pertinentes neste cenário obesogênico, que exige desconstruções e novos sentidos culturais.

Num cenário cultural, a imagem retratada por Cândido Portinari em 1944 (Figura 1), que apesar de seu caráter contemporâneo, expressa uma faceta da imagem arquetípica do Comer, trazendo uma realidade e uma falta que marcaram a emergência de um preencher do corpo no imaginário cultural. Essa falta, num contexto da saúde e no que tange às influências do Complexo Cultural e do Comer, marca a necessidade de um preencher que muitas vezes se faz excessivo e desnaturado, a qual deve ser considerada no tratamento multidisciplinar da obesidade, por meio de estratégias terapêuticas que contemplem essa realidade e a visão de totalidade psíquica.

\section{Referências}

Araújo, F. C. de. (2002). Da Cultura ao Inconsciente cultural: Psicologia e Diversidade étnica no Brasil Contemporâneo. Psicologia, Ciência e profissão, 22(4), 24-33.

Busse, S. R. (2004). Anorexia, bulimia, obesidade. Barueri: Manole. 
Dalí, S. (2016). Les Diner de Gala. Alemanha: Taschen.

DaMatta, R. (1986). O que faz o brasil, Brasil? Rio de Janeiro: Rocco.

Gadotti, C. M.; Borges, M. B. F.; \& Sampaio, S. M. D. (2017). Processar, elaborar, digerir: transtorno alimentar na contemporaneidade, leitura arquetípica. Junguiana, 35(2): 47-58.

Gozawa, J. (2009). The Cultural Complex and Transformative Learning Environments. Journal of Transformative Education. 7(2): 114-133.

Henderson, J. (1984) Cultural Attitudes in Psychological Perspective. Toronto: Inner City Book.

Instituto Brasileiro de Geografia e Estatística. (1975). Estudo Nacional da Despesa Familiar 19741975. Rio de Janeiro: Instituto Brasileiro de Geografia e Estatística.

Instituto Brasileiro de Geografia e Estatística. (2009) Pesquisa de Orçamentos Familiares 2008-2009. Rio de Janeiro: Instituto Brasileiro de Geografia e Estatística.

Jacobi, J. (2017). Complexo, Arquétipo e Símbolo na Psicologia de C.G. Jung. Rio de Janeiro: Vozes.

Jung, C. G. (2011a). Estudos Experimentais. (Vol. 2). Rio de Janeiro: Vozes.

Jung. C. G. (2011b) Psicologia do Inconsciente. (Vol. 7/1). Rio de Janeiro: Vozes.

Jung, C. G. (2011c). O Eu e o Inconsciente. (Vol. 7/2). Rio de Janeiro: Vozes.

Jung, C. G. (2011d). Natureza da psique. (Vol. 8/2). Rio de Janeiro: Vozes.

Jung, C. G. (2011e). Os arquétipos e o Inconsciente Coletivo. (Vol. 9/1). Rio de Janeiro: Vozes.

Jung, C. G. (2011f). Aion. (Vol. 9/2). Rio de Janeiro: Vozes.

Jung, C. G. (2011g). A vida simbólica. (Vol. 18/1). Rio de Janeiro: Vozes.

Kimbles, S. L. (2000). The cultural Complex and the myth of invisibility. Em T. Singer (ed.), The vision thing: myth, politics and psyche in the world. New York: Routledge.

Kimbles, S. L. (2014). Phantom Narratives. The Unseen Contributions of Culture to Psyche. New York: Rowman \& Littfefield.

Nasser, Y. B. N. (2010). A identidade corpo-psique na psicologia analítica. Estudos e Pesquisas em Psicologia, 10(2), 325-338.
Penna, E. M. D. (2004). O paradigma junguiano no contexto da metodologia qualitativa de pesquisa. Psicol. USP, 16(3): 71-94.

Ramos, D. G. (2004). Corruption. Symptom of a cultural complex in Brazil. In T. Singer \& S. L. Kimbles (Eds.), The cultural complex: Contemporary Jungian perspectives on psyche and society. New York: Brunner-Routledge.

Singer, T.; Kimbles, S. L. (2004). The Cultural Complex: Contemporary Jungian perspectives on psyche and society. New York: Brunner-Routledge.

Woodman, M. (2001). A Coruja era filha do Padeiro: Obesidade, Anorexia Nervosa e o Feminino Reprimido. São Paulo: Cultrix.

Woodman, M. (2002). O Vício da Perfeição: Compreendendo a Relação entre Distúrbios Alimentares e Desenvolvimento Psíquico. São Paulo: Summus.

Yakushko, O.; Miles, P.; Rajan, I.; Bukjo, B.; \& Thomas, D. (2016). Cultural unconscious in research: integrating multicultural and depth paradigms in qualitative research. Journal of Analytical Psychology, 61(5): 656-675.

Maria do Desterro de Figueiredo (orcid.org/00000002-0564-6308) possui graduação em Psicologia pela Universidade Estadual de Maringá. Especialista em Transtornos Alimentares e Obesidade (USP). Mestre em Medicina Interna e Ciências da Saúde (UFPR). Doutorado em Medicina Interna e Ciências da Saúde (UFPR). Atualmente é Professora e Supervisora de Estágio no curso de Psicologia do Centro Universitário Franciscano do Paraná - FAE. Coordenadora do LATOS - Laboratório de Pesquisa em Transtornos Alimentares, Saúde Mental e Obesidade e Coordenadora do GAPO - Grupo de Apoio Psicológico a Obesos, vinculados ao curso de Psicologia da FAE. Email: maria.defigueiredo@fae.edu

Stella Nabuco Nasser (orcid.org/0000-0003-25362182) é graduanda em Psicologia pela FAE - Centro Universitário e integrante do Laboratório de Pesquisa em Transtornos Alimentares, Obesidade e Saúde Mental LATOS/FAE. Email: nasser.stella@gmail.com

Armando de Oliveira e Silva (orcid.org/0000-00027392-0081) é graduado em Psicologia pela Pontifícia Universidade Católica do Paraná. Psicólogo clínico e supervisor. Email: armandoos@uol.com.br

Rosana Bento Radominski (orcid.org/0000-00034035-106X) possui graduação em Medicina (UFPR), especialização em Medicina do Esporte (UNIFESP), mestrado em Medicina Interna (UFPR) e doutorado em 
Endocrinologia e Metabologia (USP). É colaboradora do Serviço de Endocrinologia e Metabologia da UFPR (SEMPR), responsável pelo ambulatório de obesidade infanto-juvenil do Hospital de Clínicas da UFPR na Unidade de Endocrinologia Pediátrica. Docente nos cursos de Pós-graduação em Medicina Interna e Pósgraduação Segurança Alimentar do Departamento de Nutrição (UFPR). É membro do Departamento de Obesidade da Sociedade Brasileira de Endocrinologia e Metabologia. Email: rosanaradominski@gmail.com

Recebido em 02.05.2019

Primeira Decisão Editorial em 10.10.2019

Aceito em 08.11.2019 